\title{
The Remote Experimentation as the Practical-Oriented Basis of Inclusive Engineering Education
}

\author{
https://doi.org/10.3991/ijoe.v15i05.9752 \\ Heinz-Dietrich Wuttke( $\left.{ }^{\varpi}\right)$ \\ Ilmenau University of Technology, Ilmenau, Germany \\ dieter.wuttke@tu-ilmenau.de \\ Anzhelika Parkhomenko, Artem Tulenkov, \\ Galyna Tabunshchyk, Andriy Parkhomenko \\ Zaporizhzhia National Technical University, Zaporizhzhia, Ukraine \\ Karsten Henke \\ Ilmenau University of Technology, Ilmenau, Germany
}

\begin{abstract}
The challenges and solutions for inclusive engineering education are discussed in this paper. We propose remote experimentation as the practicaloriented basis to train engineers with disabilities in the fields of Computer Science and Information Technologies. The structure and the functionality of international GOLDi network that unites partner universities from Germany, Australia, Ukraine, Armenia and Georgia is given. The possibilities of REIoT complex for studying the features of embedded systems design and Internet of Things technologies as well as an overview of ISRT laboratory for embedded software development and testing are given. The presented Remote Laboratories are successfully used to improve educational services quality and accessibility as well as to strengthen the practical component of the learning process.
\end{abstract}

Keywords-People with disabilities, remote laboratory, electromechanical physical system, control unit, embedded system, Internet of Things, Smart House.

\section{Introduction}

The whole civilized world promotes the idea of a comprehensive integration of people with disabilities into the ordinary life. Nevertheless, inclusion rate in Ukraine is only $7 \%$. For comparison: in Lithuania it covers $90 \%$, in Poland - $42 \%$, in Slovakia - 42\%, in Hungary - 57\%, in Italy - 99\%, in Norway - 90\%, in France - 25\%. [1] According to data of Ministry of Social Policy of Ukraine, the number of people with disabilities, relatively counted, has doubled compared to 1990 and amounts approximately 3 million people. Almost $80 \%$ of people with disabilities are of working age [1]. The main problem for this category of population is equal access to all possibilities of modern civilization. Moreover, one of the most fundamental issues is educa- 
tion. Therefore, the materials of this paper were recently discussed at the international conference in Ukraine and should be disseminated [2].

According to the statistics, among the 2.5 million students of Ukrainian HEIs of IIV levels of accreditation there are just over 10 thousand - students with special needs. In practice, this is less than $1 \%$ of the total number of people with disabilities of working age (up to 40 years) [1]. The reason for this is that, unfortunately, the conditions and infrastructure for the education of such categories of students do not exist. In recent years, this problem has worsened due the events in the zone of conflict in the east of Ukraine and on the occupied territory of the Crimea. Thus, the number of people with special needs is permanently growing. They are refugees, internally displaced persons, and disabled people (civilians as well as participants in antiterrorist operations) injured in conflict zones [3].

Therefore, in parallel with traditional tasks of the educational process, it is necessary to regulate the issues of the organizing of studies for people with special educational needs. Certainly, these tasks are new for educational system in Ukraine, but the Ministry of Education and Science, university administrations, the international community, organizations and authorities from different countries must solve them together [4].

The physical presence in the auditorium, taking into account the state of physical health, the psychological aspects of communication and the working conditions associated with checkpoints and transport in conflict zones are the key issues in organizing the educational process for these specific categories of students.

Thus, the implementation of modern technologies of distance learning that would allow reducing the face-to-face communication between the teacher and the student without worsening the final academic results, will contribute to the increase of the amount of students with special educational needs.

The fields of study Computer Science and Information Technology are the most popular among the entrants to the HEIs from such special categories of young people. According to market requirements, engineers in these specialties must be able to design, implement and verify advanced embedded electronic systems, cyber physical systems, to realize Internet of Things technologies (IoT), etc. Therefore, the application of new teaching approaches and modern tools for educational process of these specialties is very important.

Today there are many various distance-learning systems, which are developed and successfully implemented in the world for remote access to the theoretical components of courses and tests. The most well-known are: web Tutor LMS, Moodle, ATutor, Eliademy, Forma LMS, Dokeos, ILIAS, Opigno, and OLAT.

However, the use of practical experiments and work with equipment, especially for students of technical specializations, is still very important. Therefore, the modernization of engineering education should include a change of theoretical way of learning to practice-oriented competence-based approach as well as use of modern hardware and software platforms for the study of industrial design methods. Modern on-line laboratories can act as such a platform. 
The International Association of On-Line Engineering (IAOE) and the Global OnLine Laboratory Consortium (GOLC) promote the development, dissemination and application of on-line technologies and their impact on society [5].

Nowadays, the Remote and Virtual Labs (R\&VL) are successfully developed and implemented worldwide, but for Ukraine, such experience is new and it requires investigation and implementation. Nevertheless, the development and practical application of novel educational resources based on remote access experiments and installations is an urgent task, as they can offer qualitatively new technologies and methods of vocational training [6-9].

The most popular R\&VL for engineering education laboratories in the fields of control engineering, robotics and electronics are iLab, WebLab Deusto, VISIR, GOLDi, RELLE, WEBENCH, Labshare and others [10-11]. They provide plenty of opportunities for working with unique equipment and for safety performing of different experiments. As investigation [12] has shown, its main problems are the limited number of users that can work with the equipment simultaneously, as well as the lack of a common infrastructure. Therefore, today in the world experience of R\&VL the clear trends are information aggregation of existing Internet resources with access to laboratory experiments as well as unification of labs architecture and hardware/software solutions [13-16]. On this basis, we can recommend the usage of GOLDi (Grid of Online Lab Devices), which offers a worldwide network of laboratories and thus more opportunities for the effective work of students [17].

\section{GOLDi as Effective Platform for Practical-Oriented Engineering Education}

The Integrated Communication Systems Group at the Technische Universität Ilmenau, Germany, developed hardware and software of GOLDi. Today, the GOLDi network of laboratories brings together the partner universities of Germany, Ukraine, Georgia, Armenia and Australia. Students can use any equipment available on-line at any of these universities. They can observe that the students from other countries have the same learning tasks, the same equipment and the same training base and it serves as a strong motivation for them.

GOLDi servers and GOLDi infrastructures were installed at Ukrainian HEIs (Zaporizhzhia National Technical University (ZNTU, Zaporizhzhia), Boris Grinchenko Kiev University (BGKU, Kiev), Donbass State Engineering Academy (DSEA, Kramatorsk)) in the frame of the international educational TEMPUS projects ICo-op and DESIRE [18-19] and are organized as a cloud-solution (Fig. 1).

The features of this cloud architecture are as follows [20-21]:

- Maintenance of the whole system on one central location: goldi-labs.net.

- All partner universities have the same GOLDi version.

- New functionalities are immediately available for all partners.

- Usage of all partner labs with one central goldi-labs.net user account. 
- The user can determine which lab has the lowest delay (best reaction time) regarding his current geographic position and internet connection.

- Overview about all running experiments in all partner labs worldwide with the possibility to observe these experiments.

Each GOLDi client communicates with the GOLDi cloud for the central user management, experiment management and the booking management.

- All privacy-relevant data of the cloud are located in the computing department of the Ilmenau University of Technology following the GDPR [22].

- Each client application exchanges only the sensor/actuator signals directly with the local GOLDi infrastructure.

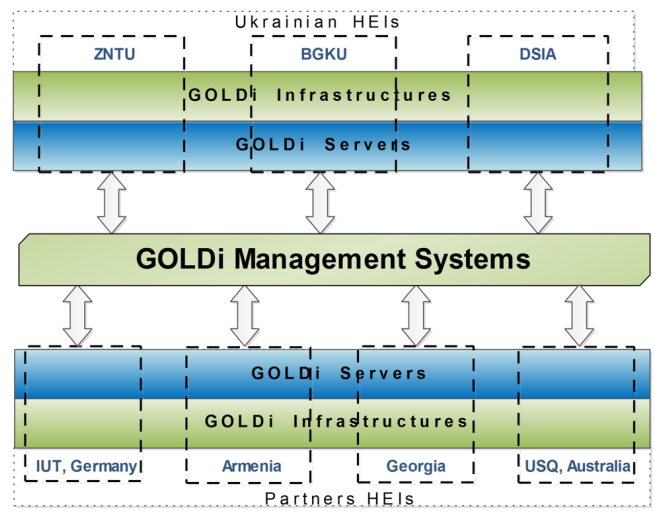

Fig. 1. GOLDi architecture

The use of GOLDi was implemented at ZNTU for such specialties as Computer Science, Engineering of Software and others. Several GOLDi physical (electromechanical) systems successfully function at the Laboratory of Embedded Systems and Remote Engineering of the Software Tools Department of ZNTU (Fig. 2).

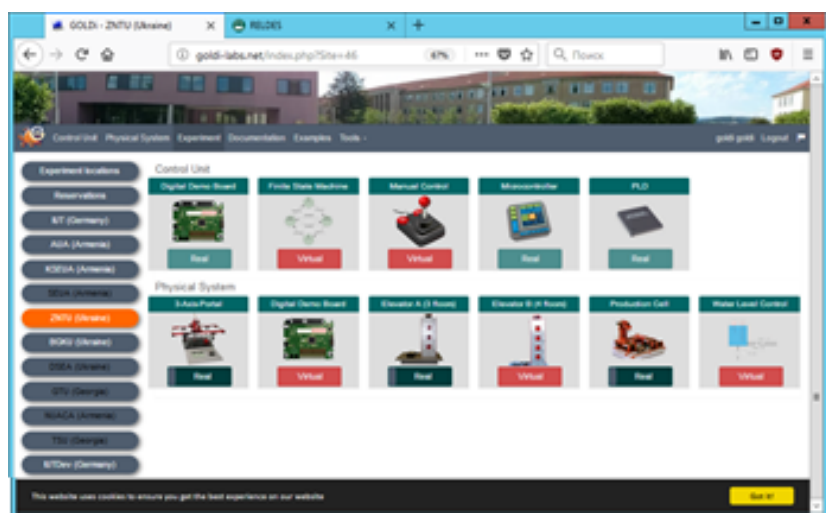

Fig. 2. GOLDi experiments configuration at ZNTU 
The great variety of experiments results from the grid structure of the connections between control units $(\mathrm{CU})$ and control objects ( $\mathrm{CO}$, electromechanical physical systems), in which any combination of real or virtual control units and control objects is possible [23-24]. To teach the development of control algorithms, different experiment configurations can be realized:

- Finite State Machines (FSM) based experiment configuration (for an abstract approach, independent of the implementation by using an FSM-interpreter),

- Microcontroller based experiment configuration (for a software-oriented implementation using microcontrollers or programmable systems on chip (PSOCs),

- Programmable Logic Devices (PLD) based experiment configuration (for a hardware-oriented design using CPLDs or FPGAs) and

- Programmable Logic Controller (PLC) based experiment configuration (for an industry-oriented approach using industrial control units).

After the configuration of the experiment, the students see the Experiment Control Panel (ECP) and have access to the actuators and sensors (Fig.3).

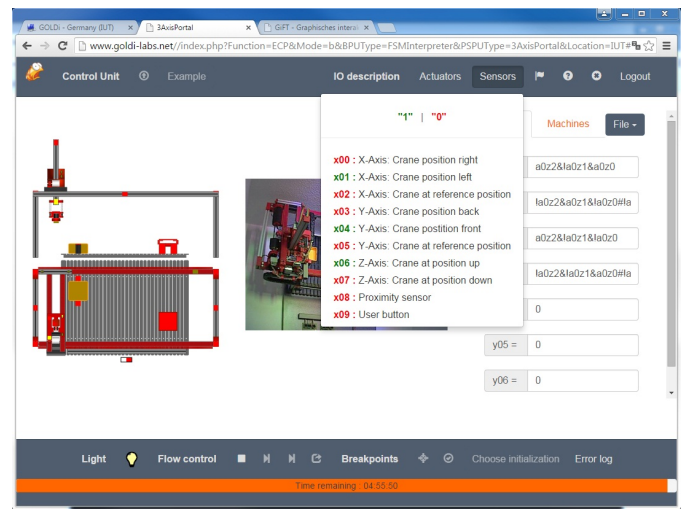

Fig. 3. GOLDI Experiment Control Panel

Via the ECP they are able to:

- Upload the synthesized/compiled designs to the CU of the experiment configuration in the laboratory.

- Handle the experiment (e.g., start, stop, reset).

- Use the interactive debug features (break at sensor/actuator changes or special conditions), single step processing, or by pausing the execution at every sensor/actuator change.

- If necessary, change environmental variables and watch the experiment by manipulating environmental variables using an I/O monitor or by observing the control of the physical system directly via a webcam.

- Choose an individual initial situation for the experiment. 
The Graphical Interactive FSM Toolset (GIFT) can be used directly within the GOLDi infrastructure and provides methods for:

- General FSM administration.

- Input the FSM as automaton graph or transition table.

- Editing edge weights, output functions and node coding.

- Simulation of single and parallel machines.

- Generation of the next-state (z) and output (y) equations.

- Generation of equations for D and JK flip-flops.

- Export of z/y equations via the ECP to the FSM-interpreter of the GOLDi system.

Fig. 4 shows the graphical FSM-input mode of the GIFT user interface.

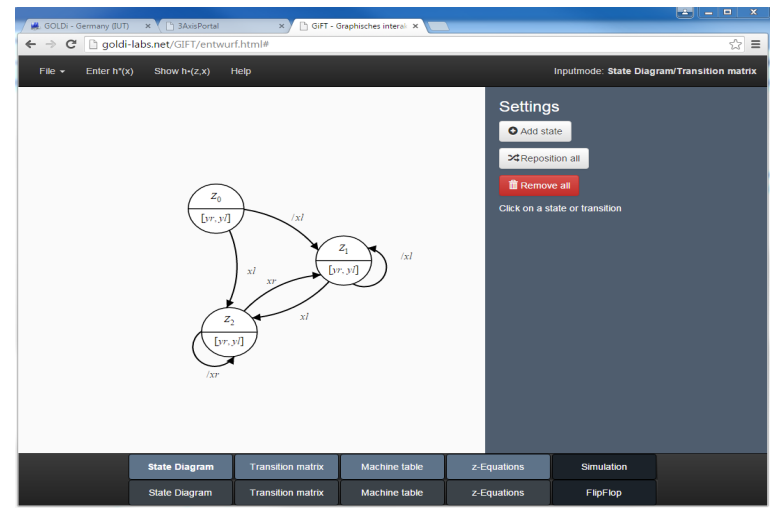

Fig. 4. GOLDI FSM-input mode of the GIFT user interface

The use case diagram in Fig. 5 shows the main steps and activities of the user, GOLDi server and experiment execution.

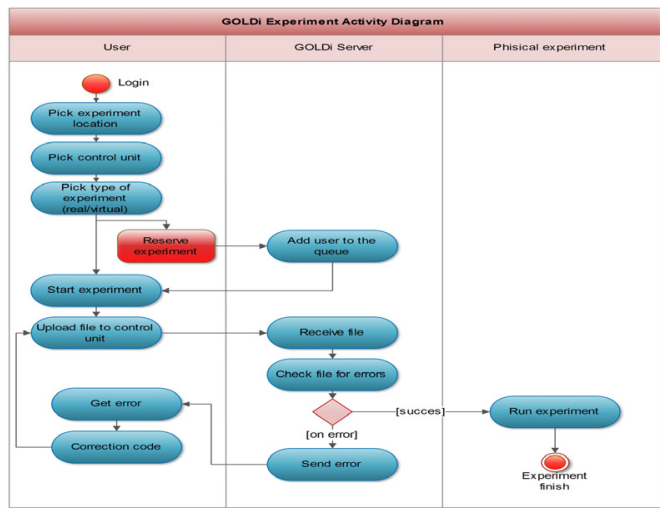

Fig. 5. GOLDi activity diagram 
Any user, who wants to access a remote experiment, must be registered in GOLDi user management system. Registered users can select an experiment location (at any university) and then configure an experiment by selecting the control unit and physical system, required for the work. If certain experiment configurations are not currently available, the user can reserve them for a later date using the GOLDi booking system.

The input data for the experiments can be prepared using different specification techniques and development tools support (GIFT and FSM-interpreter for FSM designs, microcontroller IDE (Atmel), Altera development environment (Quartus II, ModelSim) or Siemens LOGO! Software).

The input file for the control unit can be created using different languages (Assembler, C, VHDL (Very high-speed integrated circuits Hardware Description Language), AHDL (Altera Hardware Description Language), Verilog HDL or LOGO!). It is possible to use text based (enter the design by means of logical equations, truth tables) or graphically based design methods (enter the design by using block diagrams and/or schematic diagrams). Simulation of the design can be done by using different simulation tools (e.g. Qsim or ModelSim).

\section{The Features and Possibilities of Integrated Complex with Remote Control REIoT for Engineers Training}

R\&D group of Software Tools Department of Zaporizhzhia National Technical University, Ukraine, developed REIoT-complex for Embedded Systems design and IoT technologies study.

It is based on Arduino, Raspberry Pi and OpenHAB platforms and unites two subsystems: RELDES (REmote Laboratory for Development of Embedded Systems) and the Remote Laboratory Smart House\&IoT [25-26].

The use of the RELDES remote lab (Fig.6) allows students to acquire knowledge and practical skills in the area of embedded systems (ES) design. Several remote experiments in the field of ES for controlling mobile objects using Arduino, LED traffic light, servomotors, LCD and TFT displays, ultrasonic sensors are proposed for users [27-29].

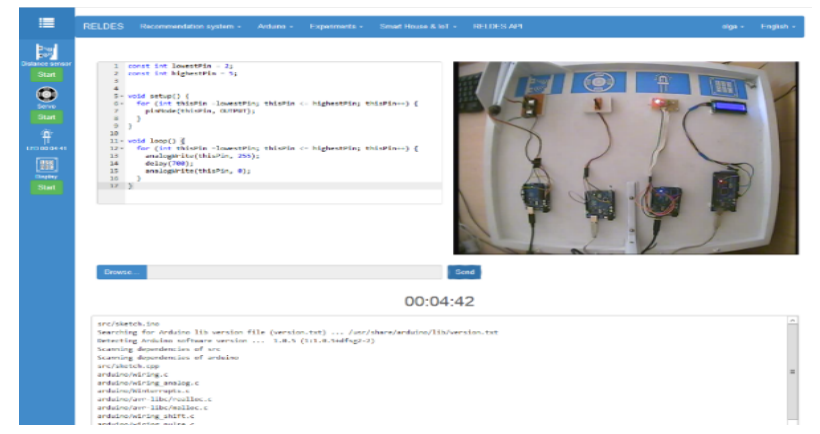

Fig. 6. RELDES experiments web-interface 
They can obtain and analyze information about finished hardware/software platforms, get recommendation about platforms to be used for their projects (Fig. 7), develop program code, and verify the hardware and software compatibility and performance of embedded systems. Remote testing of components allows a quick assessment of their appropriateness for use and the decision to integrate them into the project to reduce risks and development time.

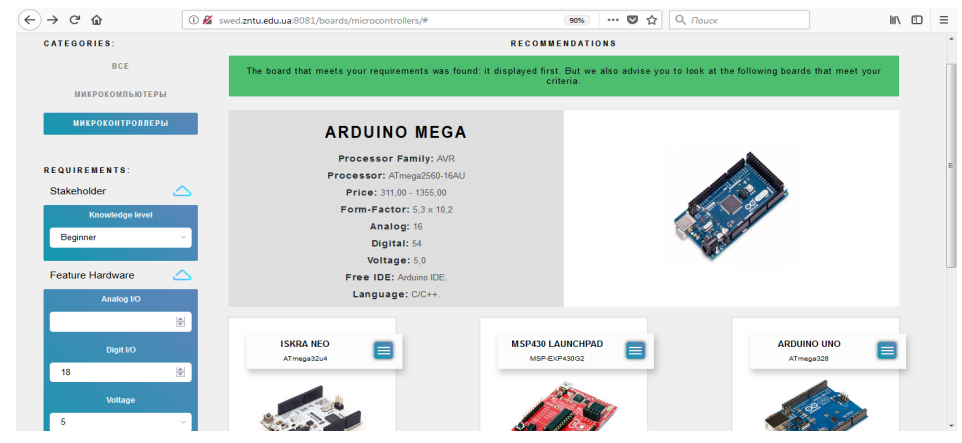

Fig. 7. RELDES recommendation system web-interface

The Remote Lab (RL) Smart House \& IoT (Fig.8) is the software/hardware platform for investigation the features of the development Smart House Systems (SHS) and the practical study of various platforms, sensors, actuators, protocols and interfaces for implementation of IoT technologies. It combines several subsystems to create a true Internet of Things for the SHS: Solar Energy Subsystem, Climate Control Subsystem, Lighting Subsystem, Access Control Subsystem, Ventilation Subsystem and others.

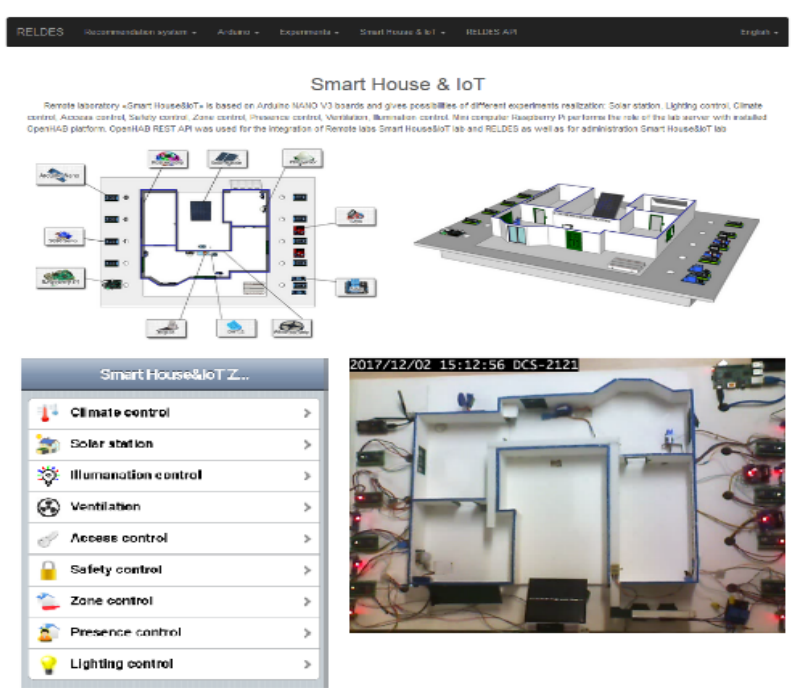

Fig. 8. Remote Lab Smart House \& IoT web-interface 
An investigation has shown that similar Smart home laboratories were established by Intel Corporation and Cornell University (Itaka, USA) [30-31]. However, Intel lab is based on only Intel equipment with the aim of its promotion and Cornell lab is controllable via voice, which is not convenient for people with voice disorders. This justifies the development of RL Smart House \& IoT based on widespread inexpensive components and acceptable control options.

The RL Smart House \& IoT provides the possibility to define the rules and the logic of operation and monitoring of the entire SHS processes or to perform remote experiments with each subsystem separately. The proposed remote experiments fit typical home automation tasks and subsystems. Based on our open information about schemas, software solutions and component suggestions, users will be able to create their own Smart House systems.

The RL Smart House\&IoT can be effectively used as a prototype of real SHS for issues of such systems as power efficiency, safety and cybersecurity investigation [32].

One set of experiments is proposed for studying the issues of resource saving and energy efficiency. They allow controlling the parameters of lighting, heating, air conditioning, ventilation and recuperation systems as well as solar energy production.

- Lighting and illumination control - studying of various lighting systems usage and control of the level of illumination in different zones.

- Climate control - control of temperature, humidity and air quality in different areas of sensors installation.

- Ventilation - principles of operation of the air ventilation system with heating and control of the flow rate parameters, temperature and humidity.

- Solar Station - the basis of obtaining and accumulating renewable energy from solar panels (Fig.9).

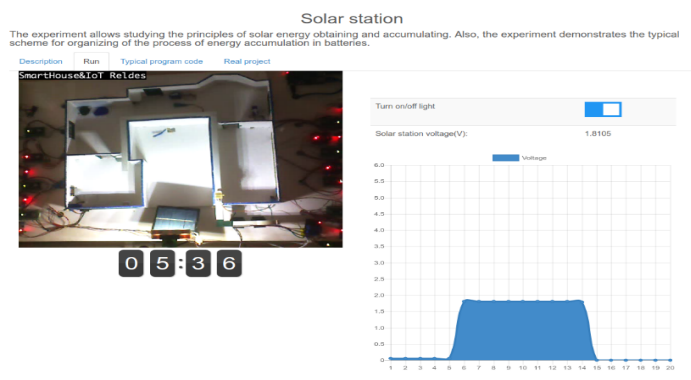

Fig. 9. Experiment Solar station web-page

Another set of experiments can be carried out for the study of safety issues, allowing monitoring the access to controlled zones and objects.

- Presence control - control of presence in the zone for effective lighting control.

- Zone control - proposes for studying the principles of security control of the perimeter of the zone. 
- Access control - proposes for studying the principles of authorization and access control systems.

- Safety control - proposes for studying the basics of security systems with motion sensors and intrusion detection systems (Fig.10).

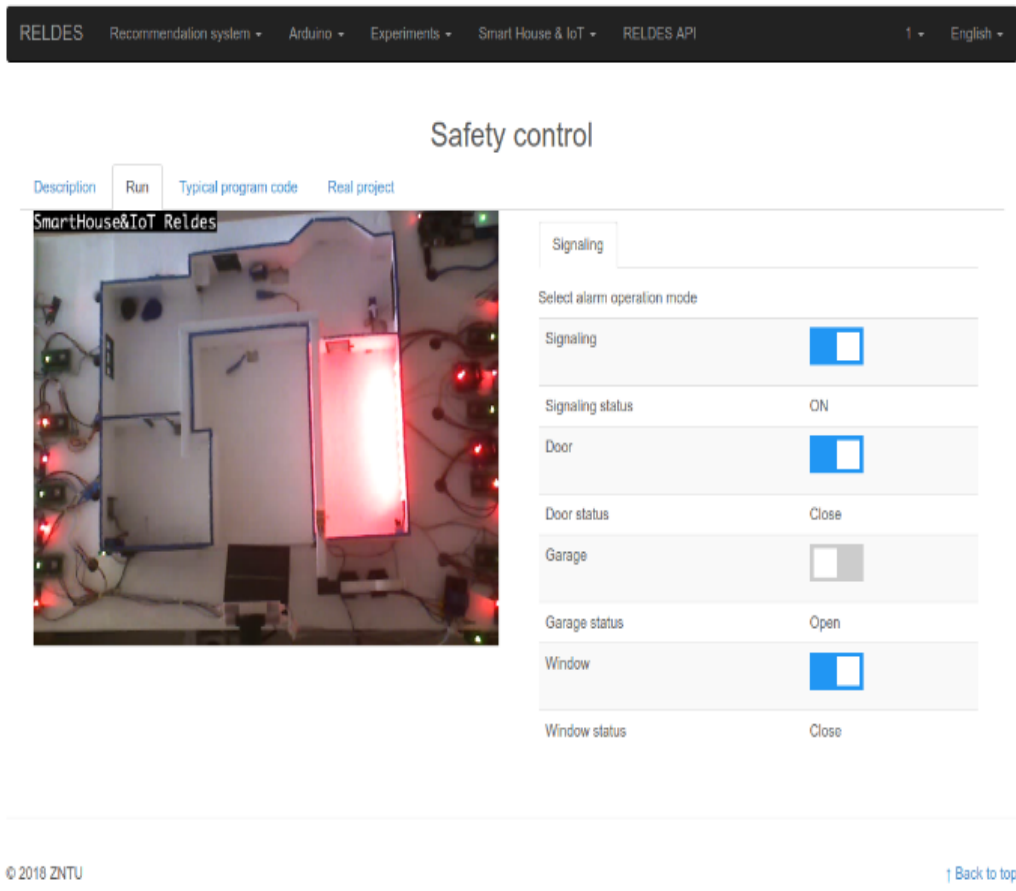

Fig. 10.Experiment Safety Control web page

The third set of experiments can be used for the study of cyber security issues that enable the use of wireless, cloud and mobile technologies for system monitoring and control, as well as for data collection and visualization.

- Wi-Fi security - principles of connecting devices via Wi-Fi protocol, checking the stability and security of the connection, as well as the demonstration of exceptional situations.

- OpenHAB control - additional features of the OpenHAB platform (my.openhab, MailControl and Telegram), which allow to control SHS through the Internet, collect device statistics, receive notifications on users mobile devices.

\section{Remote Software Development for the Embedded Systems}

Developed in ZNTU, the remote laboratory ISRT (Informational Systems on Reliability Tasks) aims to give students possibilities for remote software development in 
$\mathrm{C}++$ and Python for manipulating and testing of the connected hardware [33-34]. The aim is to prepare students for IoT software development as students have the possibility to study and experiment on different aspects of embedded systems and communication tools over the Internet.

It has an adaptive architecture based on three Raspberry Pi devices [35], which have connected hardware for the laboratory experiments. The software architecture is based on client-server approach that allows easily increase the number of connected Raspberry Pi devices and consequently expand number of the experiments (Fig. 11).

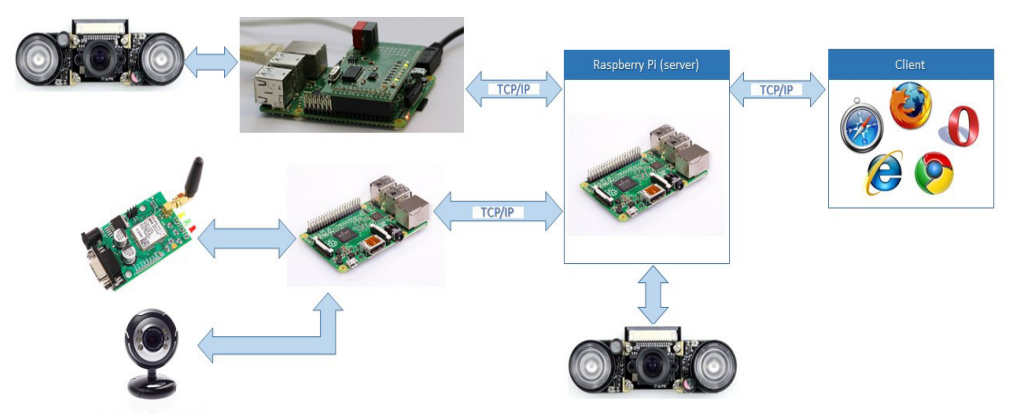

Fig. 11. Basic architecture of the ISRT

Possibilities for the remote users' access to the ISRT infrastructure were implemented by usage of web-browsers at the client machine. The interface functionality includes the administrative panel for specifying the functional units for an architecture adaptation.

Scenarios for the remote software development include manipulation with LEDs on the expansion board, manipulation with a light sensor, face detection or with the Raspberry Pi Professional Infrared Camera OV5647 (internal) or with a standard Web-camera (external), GSM module manipulation, and detection BLE devices [36].

The other set of remote experiments include developing test suits as for weboriented software as for the connected hardware. Such experiments allow students to get skills in developing unit-tests and knowledge in black box and grey box testing.

The common approach for ISRT is to use it for training purposes and as a step-bystep build-up of competences for the own project.

\section{Conclusion}

The usage of remote labs as the advanced educational resources gives students with special educational needs the opportunity to get valuable practical experience, to work with modern software and hardware as well as unique equipment, to feel their involvement in a team of like-minded people and to get the motivation for further edu- 
cation as well. New knowledge and skills can be obtained by a student confined to a bed or a wheelchair, or by a student, which cannot get to the place of study.

Based on GOLDi, REIoT and ISRT laboratories it is possible to develop different learning scenarios for the educational process in different areas: embedded electronic systems, cyber physical systems, IoT technologies, embedded software development and testing, and others.

These laboratories are constantly expanding and improving. It is planned in nearest feature to supplement the set of GOLDi experiments with Smart House set of equipment. The future work for REIoT complex will be related with an integration of recommendation system for Remote and Virtual Labs selection and effective application in the educational process. A further improvement of the ISRT is concentrated on implementing a module for data analysis.

\section{Acknowledgement}

We acknowledge support for the Article Processing Charge by the German Research Foundation (DFG) and the Open Access Publication Fund of the Technische Universität Ilmenau.

\section{$7 \quad$ References}

[1] D. Kornienko, "Inclusive education in Ukraine: It's mooring, it destroys..." [Online]. Available: https://gazeta.ua/articles/life/_inklyuzivna-osvita-v-ukrayini-toj-muruye-tojrujnuye/ 818388

[2] A. Parkhomenko, A. Parkhomenko, G. Tabunshchyk, K. Henke, and H.- D. Wuttke. "The remote labs as an effective tool of inclusive engineering education. $12^{\text {th }}$ International Conference on Perspective Technologies and Methods in MEMS Design, 2018, pp.209214. https://doi.org/10.1109/MEMSTECH.2018.8365735

[3] Report on the human rights situation in Ukraine. [Online]. Available: http://www.ohchr.org/Documents/Countries/UA/UAReport18th_EN.pdf

[4] Education for ATO veterans: overview of the best programs. [Online]. Available: https://hromadskeradio.org/ru/programs/ tochky-opory/osvita-dlya-veteraniv-ato-oglyadnaykrashchyh-program

[5] The International Association of Online Engineering. The Global Online Laboratory Consortium. [Online]. Available: http://www.online-lab.org/

[6] P. Arras, K. Henke, G. Tabunshchyk, and D. Van Merode. "Iterative pattern for the embedding of remote laboratories in the educational process". International Conference on Remote Engineering and Virtual Instrumentation, 2015, pp.52-55

[7] M. Poliakov, T. Larionova, G. Tabunshchyk, A. Parkhomenko, and K. Henke. "Hybrid models of studied objects using remote laboratories for teaching design of control systems". iJOE 12: 7-13, 2016

[8] M. Poliakov, T. Larionova, G. Tabunshchyk, A. Parkhomenko, and K. Henke. "Remote laboratory for teaching of control systems design as an integrated system". International Conference on Remote Engineering and Virtual Instrumentation, 2016, pp. 333-340. https://doi.org/10.1109/REV.2016.7444497

[9] Remote and virtual tools in engineering: textbook. General editorship K. Henke. Zaporizhzhia, Dike Pole, 2016, 250 p. 
[10] LabsLand network for remote experimentation. [Online]. Available: https://labsland.com

[11] Go-Lab repository for online labs, apps and inquiry spaces. [Online]. Available: https://www.golabz.eu/

[12] A. Parkhomenko, A. Sokolyanskii, O. Gladkova, and S. Kurson. "Investigation of remote lab design technologies". XI International Conference on Perspective Technologies and Methods in MEMS Design, 2015, pp. 92-95.

[13] M. Tawfik, C. Salzmann, D. Gillet, D. Lowe, H. Saliah-Hassane, E. Sancristobal, and M. Castro. "Laboratory as a service (LaaS): a novel paradigm for developing and implementing modular remote laboratories". iJOE 10: 13-21, 2014

[14] D.G. Zutin, M. Auer, P. Orduna, and Ch. Kreiter. "Online lab infrastructure as a service: a new paradigm to simplify the development and deployment of online labs". International Conference on Remote Engineering and Virtual Instrumentation, 2016, pp.202-208. https://doi.org/10.1109/REV.2016.7444467

[15] P. Orduna, L. Rodriguez-Gil, I. Angulo, and O. Dziabenko. "Towards a microRLMS approach for shared development of remote laboratories". International Conference on Remote Engineering and Virtual Instrumentation, 2014, pp.375-381

[16] M. Niederstaetter, Th. Klinger, and D.G. Zutin. "An image processing online laboratory within the iLab shared architecture". iJOE 6: 37-40, 2010

[17] GOLDi. [Online]. Available: www.goldi-labs.net

[18] TEMPUS project ICo-op. [Online]. Available: www.ico-op.eu

[19] TEMPUS project DESIRE. [Online]. Available: http://tempus-desire.eu

[20] K. Henke, T. Vietzke, R. Hutschenreuter, and H.-D. Wuttke. "The remote lab cloud "goldi-labs.net". International Conference on Remote Engineering and Virtual Instrumentation, 2016, pp. 31-36. https://doi.org/10.1109/REV.2016.7444437

[21] K. Henke, St. Ostendorff, St. Vogel, and H.-D. Wuttke. "A Grid concept for reliable, flexible and robust remote engineering laboratories". iJOE 8: 42-49, 2012

[22] General Data Protection Regulation. [Online]. Available: https://gdpr-info.eu/

[23] K. Henke, St. Ostendorff, H.-D. Wuttke, T. Vietzke, and C. Lutze. "Fields of applications for hybrid online labs". iJOE 9: 20-30, 2013

[24] K. Henke, G. Tabunshchyk, H.-D. Wuttke, T. Vietzke, and St. Ostendorff. "Using interactive hybrid online labs for rapid prototyping of digital systems". iJOE 6: 57-62 2014

[25] REIoT. [Online]. Available: http://swed.zntu.edu.ua /

[26] A. Parkhomenko, A. Tulenkov, A. Sokolyanskii, Y. Zalyubovskiy, and A. Parkhomenko. "Integrated complex for IoT technologies study". Online Engineering \& Internet of Things. Lecture Notes in Network and Systems, vol. 22, pp.322-330, 2017. https://doi.org/10.1007/978-3-319-64352-6 31

[27] A. Parkhomenko, O. Gladkova, E. Ivanov, A. Sokolyanskii, and S. Kurson. "Development and application of remote laboratory for embedded systems design". iJOE 11: 27-31, 2015

[28] A. Parkhomenko, O.Gladkova, A. Sokolyanskii, V. Shepelenko, and Y. Zalyubovskiy. "Implementation of reusable solutions for remote laboratory development". iJOE 12: 2429, 2016

[29] A. Parkhomenko, O.Gladkova, A.Sokolyanskii, V. Shepelenko, and Y. Zalyubovskiy. "Reusable solutions for embedded systems design". International Conference on Remote Engineering and Virtual Instrumentation, 2016, pp.313-317. https://doi.org/10.1 109/REV.2016.7444491

[30] IoT reference implementation: how to build the Smart Home prototype. [Online]. Available: https://software.intel.com/en-us/articles/iot-reference-implementation-how-to-buildthe-smart-home-prototype

[31] Smart Home system. A wireless, voice-controllable, household system. [Online]. Available:

https://people.ece.cornell.edu/land/courses/ece4760/FinalProjects/f2012/jw937_sz369/jw9 37-sz369/jw937_sz369.html 
[32] A. Parkhomenko, A. Tulenkov, A. Sokolyanskii, Y. Zalyubovskiy, A. Parkhomenko, A. Stepanenko. "The application of the remote lab for studying the issues of Smart House systems power efficiency, safety and cybersecurity". Smart Industry \& Smart Education. Lecture Notes in Network and Systems, vol. 47, pp.395-403, 2018. https://doi.org/10.1 007/978-3-319-95678-7 44

[33] G. Tabunshchyk, D. Van Merode, P. Arras, and K. Henke. "Remote experiments for reliability studies of embedded systems". International Conference on Remote Engineering and Virtual Instrumentation, pp. 68-71, 2016

[34] G. Tabunshchyk, D. Van Merode, P. Arras, K. Henke, and V. Okhmak. "Interactive platform for embedded software development study". Online Engineering \& Internet of Things Lecture Notes in Network and Systems, vol. 22. pp. 3122.1, 2017. https://doi.org/10.1007/978-3-319-64352-6 30

[35] P. Arras, D. Van Merode, G. Tabunshchyk. "Project oriented teaching approaches for elearning environment". IEEE 9th International Conference on Intelligent Data Acquisition and Advanced Computing Systems, 2017, pp.317-320. https://doi.org/10.1109/IDAACS.2017.8095097

[36] G. Tabunshchyk, P. Arras, T. Kapliienko. "Sustainability of the remote laboratories based on systems with limited resources". Smart Industry \& Smart Education. Lecture Notes in Network and Systems, vol. 47, pp. 197-206, 2018. https://doi.org/10.1007/978-3-31995678-7 22

\section{Authors}

Heinz- Dietrich Wuttke is a senior researcher in the Integrated Communication Systems Group of the Faculty of Computer Science and Automation at the Technische Universität Ilmenau, Germany. He is a member of the International Association of Online Engineering (IAOE). E-mail: dieter.wuttke@tu-ilmenau.de

Anzhelika Parkhomenko is PhD, Associate professor of Software Tools Department of Faculty of Computer Science and Technologies at Zaporizhzhia National Technical University, Ukraine. E-mail: parhom@zntu.edu.ua

Artem Tulenkov is PhD student of Software Tools Department of Faculty of Computer Science and Technologies at Zaporizhzhia National Technical University, Ukraine. E-mail: injenerzntu@gmail.com

Galyna Tabunshchyk is PhD, Professor of Software Tools Department of Faculty of Computer Science and Technologies at Zaporizhzhia National Technical University, Ukraine. E-mail: galina.tabunshchik@gmail.com

Andriy Parkhomenko is PhD, Head of Educational-Methodical Department of Zaporizhzhia National Technical University, Ukraine. E-mail: parhom@zntu.edu.ua

Karsten Henke is research associate in the Integrated Communication Systems Group of the Faculty of Computer Science and Automation at the Technische Universität Ilmenau, Germany. He is a member of the International Association of Online Engineering (IAOE). E-mail: karsten.henke@tu-ilmenau.de

Article submitted 2018-10-24. Resubmitted 2018-12-17. Final acceptance 2018-12-19. Final version published as submitted by the authors. 